\title{
Modeling of Solar PV System for DC-DC Converter with improved voltage stability Using Hybrid - Optimization Techniques
}

\author{
${ }^{1}$ P.Vivek, Student Member, IEEE, ${ }^{2}$ Dr.N.B.Muthuselvan, ${ }_{13}^{3}$ J.Nanadhagopal, \\ ${ }_{1,3}$ Asst. Professor, ${ }^{2}$ Associate Professor \\ ${ }^{1,3}$ Dept of Electrical \& Electronics Engineering, Velammal Institute of Technology \\ ${ }^{2}$ Dept of Electrical \& Electronics Engineering, SSN College of Engineering \\ (Affiliated to Anna University) Chennai, Tamil Nadu, India. \\ vivekpsgped11@gmail.com,nbmselvan@gmail.com,jnandhagopal@gmail.com
}

\begin{abstract}
This research paper aims at developing a hybrid algorithm for maintaining constant voltage from solar power cell. This is achieved by applying nominal tracking ability of the solar panel. The solar panel cannot give maximum power to the load at all times due to the load mismatch happening due to the various environmental conditions. The various Maximum Power Point Tracking (MPPT) methods that are being used can track the power to its rated value but cannot be able to maintain a constant output to the load for varying condition.
\end{abstract}

\section{INTRODUCTION}

The demand for energy is increasing at an alarming rate in the world. Thus the focus on renewable energy sources is being implemented across the globe for the best utilisation of the available energy on the Earth. Some of the energy sources include solar, water, wind, etc. But the scope of the renewable energy sources is not upto the level due to their reliability throughout the year based on various reasons. Also for meeting a satisfying load demand the initial cost for such systems are much high. In spite of their cleanliness and nonpolluting, these sources are not much utilised because of the above disadvantages. Various methods [1] are being proposed for increasing the efficiency of various renewable energy systems.

One of the most common renewable energy sources is the solar. Solar Energy can be converted to electrical energy by two different ways: one is solar thermal method and another one is by solar photo voltaic method. In solar thermal method, it is similar to AC power generation using steam generation without using fossil fuel. Solar thermal is similar to conventional AC electricity generation by steam generation excepting that instead of fossil fuel whereas in a solar photo voltaic it uses the cell made of silicon or some other kind of semiconductor materials which converts the incident light energy i.e., the photons present in the sunlight to DC electricity.

This paper focuses on developing a hybrid algorithm and its implementation which senses the output of the converter and this value is compared with the rated output of the converter module so that required duty can be generated to trigger the circuit so that the required output voltage is maintained and correspondingly the maximum power is transferred across to the load without any deviation so that the efficiency of the panel is always kept near to its nominal value. The hybrid algorithm is developed in conjunction with a boost converter with the simulation being done on a $50 \mathrm{~W}$ peak at $17.44 \mathrm{~V}$ and $2.86 \mathrm{~A}$ solar panel.

\section{PROPOSED SYSTEM OVERVIEW}

Figure . 1 shows the overall model of the system. It consists of a solar panel which is connected to the voltage sensing module which senses the voltage and current. This sensing module is connected to the "Optimization Algorithm". This algorithm processes the voltage and current to check for MPP [2] of the system. The algorithm continues to increase the optimum operating point till the MPP of the panel is reached pertaining to that illumination. Thus this system is a multistep duty generator which varies according the voltage that is sensed at the output. The process repeats till the required voltage is obtained.

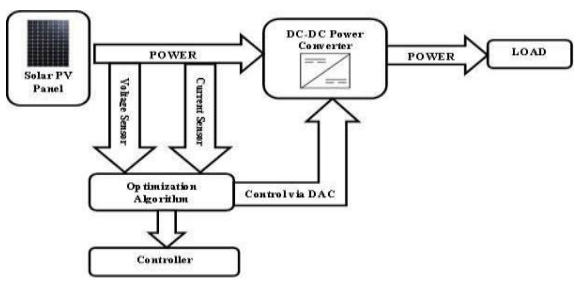

Figure 1. System Block Diagram

The optimization algorithm is a combination of two algorithms namely Perturb \& Observe (P\&O) and Particle Swarm Optimization (PSO). The flowchart of our algorithm herewith is given in Figure .2 


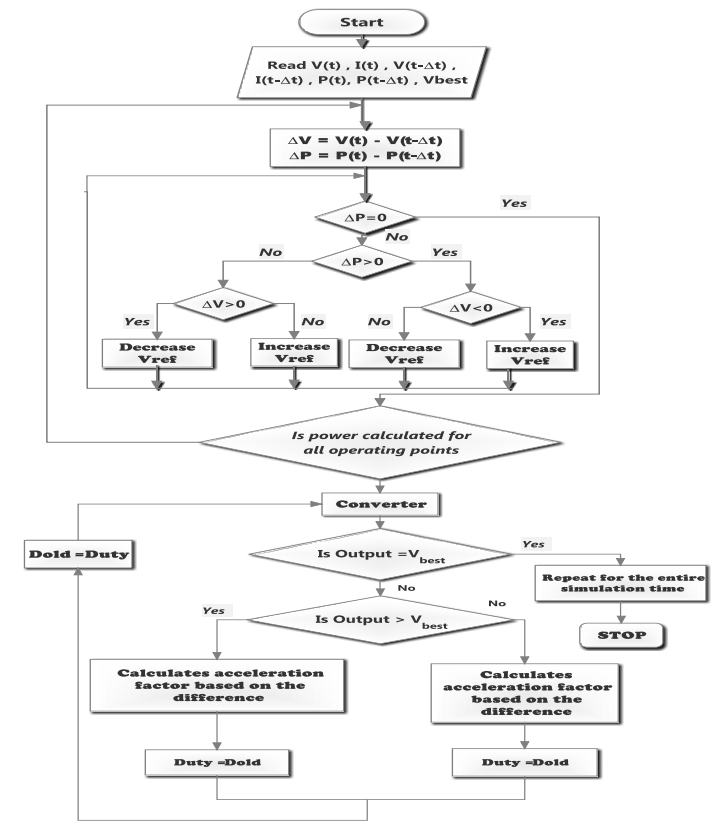

Figure 2. Flowchart of Proposed System

\section{OPTIMIZATION ALGORITHM}

The optimization algorithm forms the heart of the paper. The hybrid algorithm is the combination of the above mentioned two algorithms. It nullifies the limitations of the individual algorithms. P\&O algorithm arrives at the output with less operating time but has large number of oscillations at steady state and the step size is quite small. In PSO method though the step size is large and oscillations is less, its time period is little high. By combining these two we can get a resultant algorithm that has larger step size, less operating time and fewer oscillations at steady state.

The algorithm involves of two modules where the initial part is a P\&O model which is used to track the MPP from the solar panel pertaining to the illumination level falling on it. This tracks the panel power value. After this is done successfully the algorithm flows to its next part which contains the control functions as in PSO. Note that PSO model is not used directly in this system. Only its generic idea of defining a personal best and global best to the particle is handled here. In this case the particle is the voltage parameter. The converter output is fed back to form a close loop in which the voltage is checked to see if it has reached the global best i.e. the required output. The personal best values of voltage are updated periodically thus maintaining the flow of algorithm. Since the acceleration factor is calculated as per the voltage level using feedback system, the oscillations are reduced to a greater amount when compared to the conventional system. Is there is any change in voltage level the feedback system detects it immediately and the necessary control statements are carried out. This indicates that the operating time is relatively high. This proves that the hybrid algorithm is a great alternative to the existing method.
The algorithm is well defined by Figure 2. Thus the aim of this algorithm is to arrive at a solution pertaining to constant output voltage with tracking the MPP at that point. The overall system modeling along with the results are mentioned in the fore coming chapters.

\section{SYSTEM MODELLING}

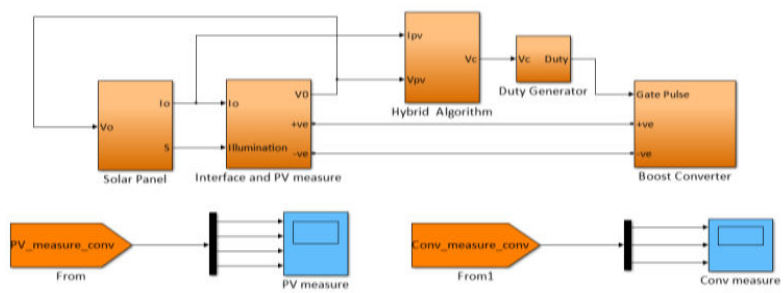

Figure 3. The overall system model which is being implemented in the MATLAB.

\section{A. Solar panel}

The equivalent circuit of solar panel is shown (Figure 4) but a reverse biased diode that is shunted across a resistor Rsh.

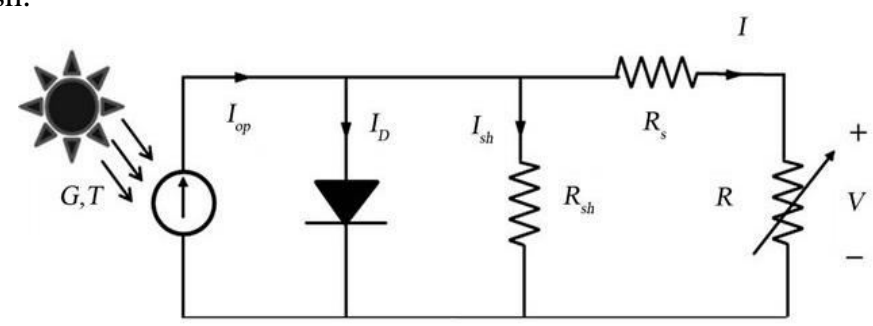

Figure 4. Equivalent circuit of solar panel

The solar panel can also be modeled in the MATLAB using the four basic empirical equations [3] as given in Figure. 5. 


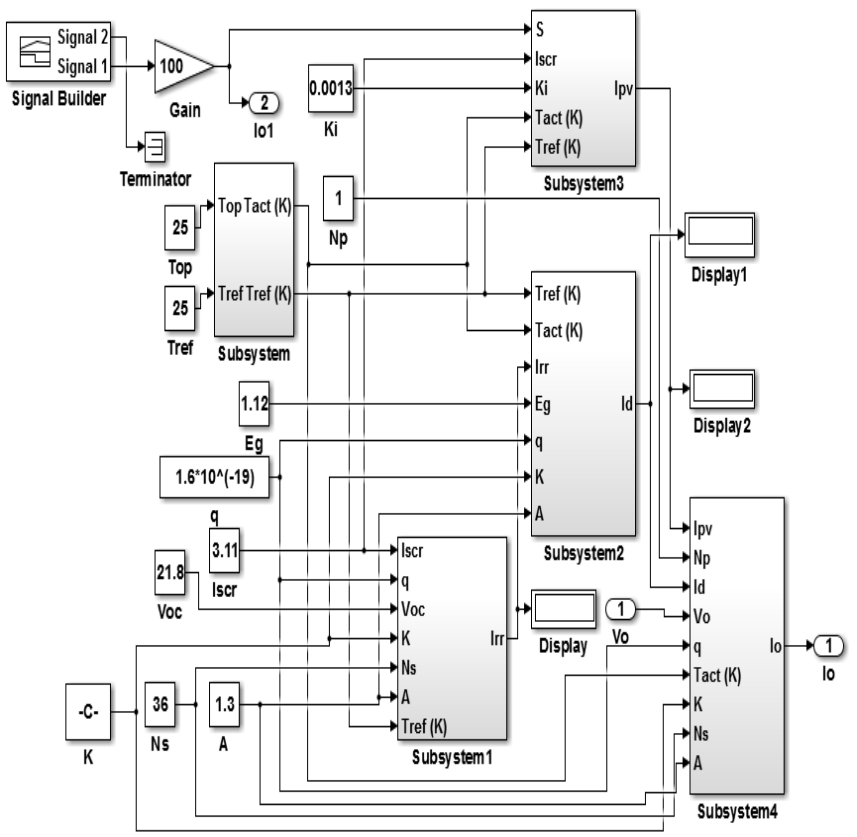

Figure 5. Solar panel model-Subsystem

$$
\begin{aligned}
& I_{r r}=I_{s c r} \div\left[e^{\left(q \times \frac{V_{o c}}{K * N_{s} * A * T_{r k}}\right)}-1\right] \\
& \left.I_{d}=I_{r r} *\left(T_{a k} / T_{r k}\right)^{3} * e^{[(E g * q / K * A)}\right)^{\left.*\left\{a / T_{r k}-1 / T_{a k}\right\}\right]}
\end{aligned}
$$$$
I_{P V}=\left[I_{s c r}+\left(K_{i} *\left(T_{a k-} T_{r k}\right)\right)\right] * S / 100
$$

$$
I_{o}=N_{p} I_{p v}-N_{p} I_{d}\left\{e^{\left[\left(\frac{q}{N s^{*} A^{*} K^{*} T a k}\right) *\left(V_{o}+I_{o}+R_{s}\right]\right.}-1\right\}^{\prime}
$$

Each solar cell has its own voltage-current (V-I) characteristics. The problem with extracting the most possible power from a solar panel is due to nonlinearity of the characteristic curve.



Figure 6. Solar Panel Characteristics

The solar PV characteristic shown in the Figure 6. has two curves, one reflects the behavior of the current with respect to incremental change in voltage $\&$ the other curve is the incremental change power w.r.t voltage in and it is shown by the equation $\left(\mathrm{P}=\mathrm{I}^{*} \mathrm{~V}\right)$.

When the P-V curve of the module shown in the table III is observed, one can locate single maxima of power where the solar panel operates at its optimum. The result is the need for a system to constantly track the P-V curve to keep the operating point as close to the maxima as much as possible while energy is extracted from the PV array.

\begin{tabular}{cc}
\hline \hline \multicolumn{2}{c}{ The electrical specifications of the PV module. } \\
\hline Maximum power $\left(P_{\max }\right)$ & $50 \mathrm{~W}$ \\
Voltage @ $\mathrm{P}_{\max }\left(V_{m p}\right)$ & $17.44 \mathrm{~V}$ \\
Current @ $\mathrm{P}_{\max }\left(I_{m p}\right)$ & $2.86 \mathrm{~A}$ \\
Short-circuit current $\left(I_{s c}\right)$ & $3.11 \mathrm{~A}$ \\
Open-circuit voltage & $21.8 \mathrm{~V}$ \\
$\left(V_{o c}\right)$ & $\pm 5 \%$ \\
Tolerance & $13 \mathrm{~A}$ \\
Maximum System & Voltage
\end{tabular}

\section{B. Sensing modules}

The sensing modules implemented in the hardware for the voltage and current are based on the working principle of Hall Effect. These modules produce the output digital values corresponding to the input current or voltage which can be utilised in the optimization algorithm.

\section{Controller}

The controller is the system which generates the gating pulses for the power electronic switch. Figure. 8 shows the MATLAB model for the controller. The hybrid algorithm produces a control voltage which is given to the controller .

The controller model contains a repeating sequence of certain frequency which produces duty depending on the control voltage. This generated duty is given as input to the converter for switching purpose. The frequency in which the duty is generated plays an important role in the final result. 




Figure 7. Controller model in MATLAB

\section{Converter}

The converter module implemented in our system is a boost converter. The boost converter is basically a DC-DC converter which produces an output voltage greater than the input voltage whose magnitude depends on the duty cycle applied to the converter. The boost converter is designed in conjunction with required output. The filter values of $\mathrm{L}$ and $\mathrm{C}$ are calculated with the view of reducing the peak voltage and ripples. Figure 8. shows the MATLAB implementation of the boost converter.

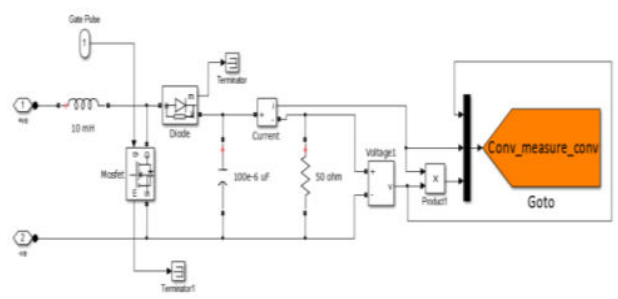

Figure 8. DC-DC Converter model in MATLAB

\section{E. Optimization Algorithm}

The hybrid algorithm is implemented in the MATLAB as an embedded function which produces a numerical control voltage for the controller. The control voltage as said before produces a duty corresponding to MPP which is supplied to the boost converter to get the required output.

\section{F. Boost converter}

DC-DC converter plays a crucial role in the system as it regulates the output voltage. The converter used here is the BOOST converter. It is a type of switch mode supply. As the name suggests the boost converter produces an output greater than the input voltage depending on its switching sequence. If the input is DC the signal is directly taken as input, if it is $\mathrm{AC}$ then it is rectified and then given as input to the converter.

\section{RESULTS AND VALIDATION}

It is well known that the illumination of the sun will not be same due to environmental changes. Thus the power from the panel also varies according to the illumination. The proposed system is able to track the varying illumination without any deviations. Simulation is carried for illumination level of a particular day i.e. illumination level as shown in Table I during the date $22^{\text {nd }}$ March 2017(Summer) has been taken as reference. The corresponding result for both conventional and proposed method is shown in Figure.15 and from the Figure. 10 it is clear that the proposed method is able to track the change in illumination with fewer oscillations and ripples.

\section{TABLE I. ILLUMINATION DATA ON 22 $2^{\mathrm{ND}} \mathrm{MARCH} 2017$}

\begin{tabular}{cccc}
\hline $\begin{array}{c}\text { Time } \\
\left(\begin{array}{c}\text { Hour } \\
\text { s) }\end{array}\right.\end{array}$ & $\begin{array}{c}\text { Illuminati } \\
\text { on }\left(\mathrm{W} / \mathrm{m}^{2}\right)\end{array}$ & $\begin{array}{c}\text { Time } \\
(\text { Hour } \\
\mathrm{s})\end{array}$ & $\begin{array}{c}\text { Illuminati } \\
\text { on } \\
\left(\mathrm{W} / \mathrm{m}^{2}\right)\end{array}$ \\
\hline $06: 00$ & 2.7 & 12.30 & 952.3 \\
$06: 30$ & 69 & 13.00 & 945.2 \\
$07: 30$ & 135.3 & $13: 30$ & 938.1 \\
$08: 00$ & 228.3 & $14: 00$ & 898.9 \\
$08: 30$ & 321.3 & $14: 30$ & 858.9 \\
$09: 00$ & 437 & $15: 00$ & 789.9 \\
$09: 30$ & 552.7 & $15: 30$ & 720.9 \\
$10: 00$ & 667.5 & $16: 00$ & 624.8 \\
$10: 30$ & 782.3 & $16: 30$ & 528.7 \\
$11: 00$ & 841.95 & $17: 00$ & 414.75 \\
$11: 30$ & 901.6 & $17: 30$ & 300.8 \\
$12: 00$ & 926.95 & $18: 00$ & 184.2 \\
& & $18: 30$ & 67.6 \\
\hline \hline
\end{tabular}

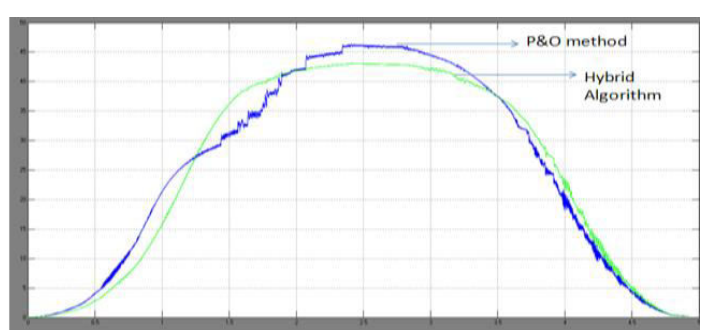

Figure 9. Comparison of power output for the above table of illumination

The various other parameters such as the output voltage, Panel Voltage and Panel current are also having been simulated and verified. Figure 10. shows the output of our proposed system producing a constant output voltage from the converter circuit. 


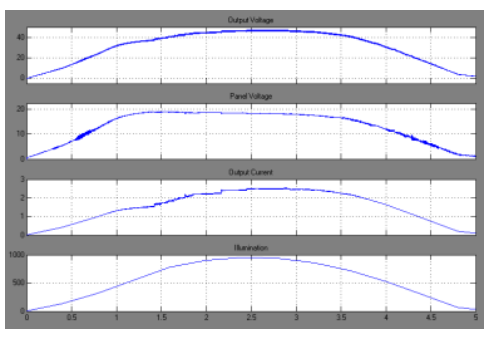

Figure 10. Simulation output of proposed system

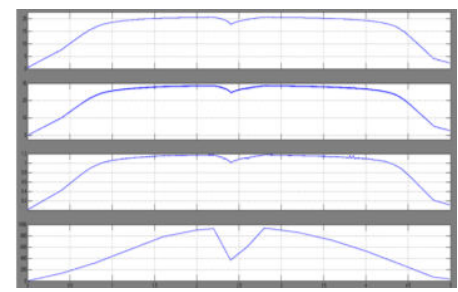

Figure 11. Response of the system during sudden dip in the illumination

The voltage level in Figure 10. shows that in order to track constant voltage some sacrifice in power is inevitable. This is because in the event of tracking constant voltage there is a reduction in current. But this reduction is within the accepted levels. While maintaining the voltage constant along with tracking the MPP of the system the operating range of the system is reduced.

The proposed system can even track any sudden dip in illumination and can act accordingly. The response of the system to the change is fairly high. Figure 11 . shows that even during sudden dip the algorithm is able to track the voltage level with response time of nearly $1 / 5^{\text {th }}$ of a second which is fairly high. Thus the proposed system can act with high accuracy, very low oscillations at steady state and able to track dynamically without any distortions.

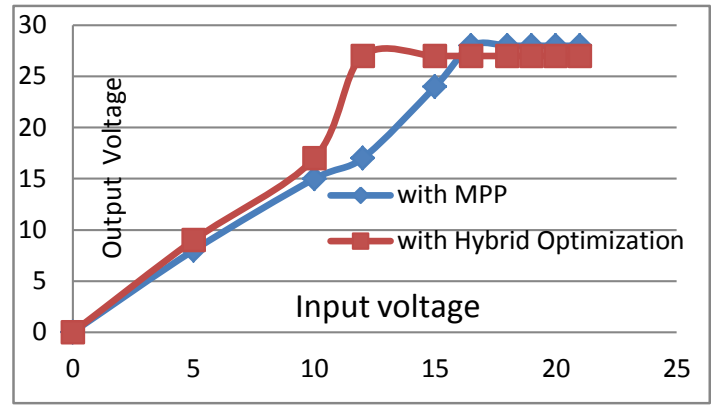

Figure 12. Voltage tracking ability
From Figure 12. it is evident that voltage tracking with MPP has a low operating range when compared to Voltage tracking with hybrid optimization. But voltage tracking with MPP has fewer oscillations, ripples and has higher efficiency.

\section{TABLE II. COMPARISON OF MPPT TRACKING}

\begin{tabular}{ccc}
\hline \hline PARAMETERS & CONVENTIONAL METHOD & PROPOSED METHOD \\
\hline Panel Voltage & 20 & 19 \\
Panel Current & 2.4 & 2.4 \\
Panel Power & 48 & 45.6 \\
Output Voltage & 43 & 45 \\
Output Current & 1.06 & 0.9 \\
Ripple Content & 4.02 & $1 \%$ \\
\hline \hline
\end{tabular}

Table III proves that the proposed system proves to be more efficient than the existing system with less ripple percentage content in the output and the values of the output parameters are also nearly equal to the conventional system

\section{CONCLUSION}

The simulation for various test cases has been simulated and the results are presented. It is proven from the sections above that the proposed model produces result with higher efficiency in both tracking of maximum power point and also in maintaining constant voltage. Though the system lacks in its operating range it makes up for it through its reduced oscillation and quicker response time. The simulation result proves that the proposed system is much in advance with the current one both in response time and in simplicity.

The hardware setup seems to be in compliance with the simulation. The converter which is used can be changed according to the application for which the algorithm is to be implemented. The ADC and PWM conversions are carefully examined throughout the process. The scope of the research work doesn't end with a single application. The constant voltage which is produced can be used in various charging appliances like battery storage system, can be used as a constant source for electrical experiments without depending on the fuel source or can be converted to AC by using inverter to supply to household appliances. Since fuel consumption is depleting the natural resources it is time to change to renewable energy as it is healthy and available in plenty. This project greatly aids in making renewable energy resources work with the same efficiency as fuel resources thereby reducing fuel consumption and global warming. 


\section{REFERENCES}

[1] Hegazy Rezk and Ali M. Eltamaly, "A comprehensive comparison of different MPPT techniques for photovoltaic systems", ELSEVIER Solar Energy, vol. 112, pp. 1-11, 2015.

[2] S.Mallika and R.Saravana Kumar, "Genetics Algorithm Based MPPT Controller for Photovoltaic System", IEEJ, Vol. 4, pp. 1159-1164, 2013.

[3] Habbati Bellia, Ramdani Youcef \& Moulay Fatima, "A Detailed Modeling of Photovoltaic Module using MATLAB", NRIAG Journal of Astronomy and Geophysics, vol.3, pp.53-61,May.2014.

[4] Ahmed Fathy, Ibrahim Zidan, Dina Amer, "An Improved Teaching Learning Based Optimization Algorithm for Simulating the Maximum Power Point Tracking Controller in Photovoltaic System", EIJEST, vol. 21, pp. 9-18, Oct. 2016.

[5] P.Vivek ,R. Ayshwarya ,S. Jessiba Amali ,A.S.Nandini Sree “A Novel Approach on MPPT Algorithm for Solar Panel Using Buck Boost Converter", in Proc. IEEE International Conference on Energy Efficient Technologies for Sustainability(ICEETS),Apr. 2016
[6] D. P. Hohm and M. E. Ropp, "Comparative study of maximum power point tracking algorithms," Proc. IEE Photovoltaic's: Res. Appl., vol. 11, no. 1, pp. 47-62, Jan. 2003.

[7] T. L. Nguyen and K. S. Low, "A global maximum power point tracking scheme employing DIRECT search algorithm for photovoltaic systems," IEEE Trans. Ind. Electron., vol. 57, no. 10, pp. 3456-3467, Oct. 2010.

[8] S. Yuvarajan, Dachun Yu, Shanguang Xu, "A novel power converter for photovoltaic applications", Journal of Power Sources, Elsevier Science, Vol. 135, pp. 327-331, 2004. pp. 440-449, Mar. 2006.

[9] Jagdamba Prasad Sonkar, K.G.Upadhyay and Rajendra Singh, "Comparison study of boost converter and buck-boost converter for maximum power extraction from solar system using MPPT controller", GJESR Research paper, vol. 1, issue. 8, Sep. 2014. 